\title{
Characteristics of Poor Tuberculosis Treatment Outcomes among Patients with Pulmonary Tuberculosis in Community Hospitals of Thailand
}

\author{
Sakarn Charoensakulchai, ${ }^{1}$ Manasak Limsakul, ${ }^{1}$ Inkharat Saengungsumalee, ${ }^{1}$ Sirawich Usawachoke, ${ }^{1}$ Aticha Udomdech, ${ }^{1}$ \\ Anintita Pongsaboripat, ${ }^{1}$ Wisit Kaewput, ${ }^{2}$ Boonsub Sakboonyarat, ${ }^{2}$ Ram Rangsin, ${ }^{2}$ Picha Suwannahitatorn, ${ }^{3}$ Mathirut Mungthin, ${ }^{4}$ \\ and Phunlerd Piyaraj ${ }^{3 *}$ \\ ${ }^{1}$ Phramongkutklao College of Medicine, Bangkok, Thailand; ' ${ }^{2}$ Department of Military and Community Medicine, Phramongkutklao College of \\ Medicine, Bangkok, Thailand; ${ }^{3}$ Department of Parasitology, Phramongkutklao College of Medicine, Bangkok, Thailand; ${ }^{4}$ Department of \\ Pharmacology, Phramongkutklao College of Medicine, Bangkok, Thailand
}

\begin{abstract}
Pulmonary tuberculosis (TB) is a major global public health problem. Thailand is listed as one of the countries with a high burden of pulmonary TB. Various factors are known to contribute to unsuccessful pulmonary TB treatment. However, studies in Thailand remain limited, especially in rural settings. This study aimed to identify the prevalence and associated factors of unsuccessful pulmonary TB treatment in community hospitals. A cross-sectional study was conducted from June-July 2019. We enrolled all patients receiving treatments in four community hospitals in central Thailand. The collected data included baseline characteristics, comorbid illnesses, a history of directly observed treatment-short course (DOTS), sputum acid-fast bacilli smear results, and chest radiography and treatment outcomes. Univariate and multivariate analyses were used to identify factors associated with unsuccessful pulmonary TB treatment. A total of 786 patients were enrolled in the study. Prevalence of unsuccessful treatment was $18.7 \%$. Associated factors of unsuccessful pulmonary TB treatment were previously treated TB (adjusted odds ratio [AOR]: 2.1, 95\% CI: 1.2-3.7), existence of comorbid illnesses (AOR: $2.8,95 \% \mathrm{Cl}$ : 1.5-5.0), DOTS not performed (AOR: 2.5, 95\% Cl: 1.4-4.5), chest radiography showing multiple lung lesions at first diagnosis (AOR: 3.0,95\% Cl: 1.7-5.2), no chest radiography improvement in the first follow-up (AOR: $17.7,95 \% \mathrm{Cl}: 8.2-38.0$ ), and unknown status of chest radiography in the first followup (AOR: 48.1, 95\% Cl: 22.3-103.5). Health promotion and primary care should be implemented in the communities to achieve ultimate successful treatment.
\end{abstract}

\section{INTRODUCTION}

Pulmonary tuberculosis (TB) is an airborne infectious disease of the lower respiratory tract caused by Mycobacterium tuberculosis. Treatment outcomes are important indicators of successful TB control policy. Despite efforts to implement effective treatment for over five decades, it has been estimated that one-third of the global population has contracted $\mathrm{TB}^{1}$ and $5-10 \%$ developed disease progression during their lifetime. $^{2}$ The WHO regions reporting a high burden of TB include sub-Saharan Africa, western Pacific islands, and Southeast Asia. ${ }^{1}$ More than two million new cases were diagnosed annually in Southeast Asia. ${ }^{3}$ In the Southeast Asian region, where poverty rates are high, TB leads to a great burden on national budget expenditure. ${ }^{3}$ Tuberculosis is one of the major causes of death globally. In 2017, people with TB, who died from the disease, totaled $16 \%{ }^{2}$ An estimated 10.0 million new cases of TB occurred in $2017 .^{2}$ The WHO aimed to reduce the TB incidence rate from $\%$ to $5 \%$ annually and the mortality rate to $10 \%{ }^{2}$

Although only a small proportion of people who contracted TB will develop the disease, the proportion of disease development is higher among patients with HIV. ${ }^{1,2,4}$ HIV stimulates the progression of TB and vice versa. ${ }^{5}$ In addition, controlling TB among patients with HIV is more difficult than usual $^{4}$ because of atypical manifestations resulting from suppressed immunity. ${ }^{5,6}$ TB is a leading cause of death among patients with HIV, although antiretroviral medications are taken appropriately. ${ }^{7}$

\footnotetext{
*Address correspondence to Phunlerd Piyaraj, Department of Parasitology, Phramongkutklao College of Medicine, 315 Rajawithee Rd., Thung Phyathai Sub-district, Rajadhewi District, Bangkok 10400, Thailand. E-mail: p_phunlerd@yahoo.com
}

Thailand is listed as one of 14 countries with burdens regarding TB, HIV-associated TB, and multidrug-resistant TB (MDR-TB). ${ }^{2}$ Risk groups of TB in Thailand include prisoners and immigrant workers from neighboring countries. ${ }^{8} \mathrm{~TB}$ is also a major cause of death among both male and female populations in Thailand. ${ }^{9}$

According to Thai National Tuberculosis Control Programme guideline (NTCPG), screening for TB is usually performed in risk groups or among patients with suspected symptoms such as chronic cough, fever of unknown origin, and unexplained significant weight loss. After receiving a diagnosis of TB, patients will be screened for HIV infection and will be given a liver function test, renal function test, eye examination, and advice for alcohol drinking cessation. Treatment regimens for adults with new pulmonary TB consist of 2 months of an intensive phase (2HRZE) and 4 months of a continuation phase (4HR), whereas patients with other conditions receive different regimens. Treatment regimens can be altered during the course of treatment according to the monitoring of patients' conditions. ${ }^{8}$

Although various health policies, such as directly observed treatment-short course (DOTS) were implemented to control pulmonary TB; however, the successful treatment rate has remained stable at $72-82 \%$ from 2002 to 2016 . $^{2}$

As of 2018, half of the Thai population is still living in rural settlements. ${ }^{10}$ Despite effective distribution of healthcare services into rural regions of the country, TB control is still remaining a challenge. ${ }^{11}$ This is a result from lowsocioeconomic status, poor TB perceptions in communities, deficiencies in poor public health knowledge on TB, difficulty to access healthcare services, and complex consultation systems in public hospitals. ${ }^{12,13}$ From the Healthcare Accreditation Institute's survey, there were a total of 727 hospitals located in rural community areas of Thailand. ${ }^{14}$ These hospitals were termed "community 
hospital"-public hospitals with missions dedicated for primary and secondary health care, which included outpatient and inpatient services to patients with common health problems. ${ }^{15}$

It has been shown that several factors including high mycobacterial load, ${ }^{16}$ atypical clinical manifestation, ${ }^{16}$ lung cavitation and miliary shadow, ${ }^{16}$ smear positive at the second month after initiation of treatment, ${ }^{17}$ immunocompromised status (HIV infection and diabetes mellitus), ${ }^{4,17,18}$ being male, ${ }^{16-18}$ older patients, ${ }^{18,19}$ and alcohol consumption ${ }^{17,20,21}$ were associated with unsuccessful treatment. However, studies remain limited of these associated factors of unsuccessful treatment outcomes in Thailand, especially in rural areas where primary and secondary prevention are important to control the disease. This study aimed to determine prevalence and associated factors of unsuccessful TB treatment in primary and secondary care settings in Thailand.

\section{MATERIALS AND METHODS}

Study population. The study population consisted of patients with TB receiving treatment in three community hospitals in Lopburi Province and a community hospital in Chachoengsao Province in central Thailand. The exclusion criteria comprised patients aged younger than 15 years, presenting extrapulmonary TB, latent TB; patients who were transferred to other healthcare units because of healthcare insurance; and patients who died from causes other than TB and TB-related illnesses. The causes of death of the patients are recorded by physicians in the TB treatment records.

Study setting. This study was conducted in three mediumsized (F2) community hospitals in Lopburi Province and one large-sized (F1) community hospital in Chachoengsao Province. F2 hospitals are community hospitals with 30 to 90 beds and have general practitioners (GPs) or family physicians providing secondary care services. F1 hospitals are community hospitals with 60 to 120 beds and have both GPs or family physicians and specialists from at least one major specialty (internal medicine, surgery, obstetrics-gynecology, pediatrics, orthopedics, and anesthesiology).

Study design. A cross-sectional study was conducted to determine prevalence and associated factors for unsuccessful TB treatment in four community hospitals in Lopburi and Chachoengsao provinces, central Thailand, from 2013 to 2018.

Data collection. Data were collected from TB treatment cards and medical records of patients from four community hospitals from 2013 to 2018 . The case record form included seven parts which included 1) baseline characteristics including gender, age, occupation, provinces, and tobacco and alcohol consumption; 2) comorbid illness and history of illness; 3) clinical manifestation at first diagnosis whether typical (chronic cough and at least one of these symptoms: hemoptysis, significant weight loss, and prolonged fever) or atypical manifestation; 4) DOTS; 5) sputum smear at first diagnosis and followed throughout the treatment course; 6) chest radiography at first diagnosis and subsequent chest radiographs; and 7) treatment outcomes, that is, cured, completed, failed, dead, default, and transferred because of drug resistant-TB (DR-TB). Although DR-TB could not be identified by the community hospitals, the patients could be suspected as DRTB if the patients did not response well with the drug regimen prescribed by the hospitals. Whenever the patients were suspected of DR-TB, their sputum will be collected and sent to tertiary hospitals for laboratory confirmation. If the patients were confirmed to have DR-TB, they would be transferred to the tertiary hospitals for further treatment by pulmonologists and the referral would be noted in the treatment record, marking the end of treatment at the community hospitals. Cured and completed outcomes were grouped in successful treatment outcomes, whereas failed, dead, default, and transferred because of DR-TB were grouped in unsuccessful treatment outcomes.

Definitions. According to the $\mathrm{WHO}$ treatment $^{22}$ and Thai NTCPG guidelines, ${ }^{8}$ pulmonary TB is a case of TB involving the lung parenchyma. Patients are considered to have smearpositive pulmonary TB when one or more sputum smear specimens at the start of treatment are positive for. Smearnegative pulmonary TB is considered when sputum acid-fast bacilli (AFB) smear is negative. However, culture positive for $M$. tuberculosis can also be considered or in a case where clinicians decide to treat with full course anti-TB therapy with radiographic abnormalities consistent with pulmonary TB. This involves either evidence of HIV infection, or if HIVnegative, the patient shows no improvement in response to a course of broad-spectrum antibiotics excluding anti-TB drugs, fluoroquinolones, and aminoglycosides.

At the end of treatment, patients can be classified into six groups by treatment outcomes. Patients are considered cured when their sputum AFB smear or culture is negative at the end of treatment. Treatment is considered complete when patients have completed the treatment, but do not show a negative sputum AFB smear or culture results in the last month of treatment, but the latest sputum smear is negative. Treatment is considered failed when the sputum AFB smear or culture is positive at the fifth month or later during treatment. Dead includes all patients who died from any causes during treatment. Default is defined when treatment is interrupted for 2 consecutive months or more. Transferred out is considered when patients are transferred to another healthcare unit without known outcome treatment.

Statistical analysis. This study used SPSS version 23.0 (IBM Corporation, Armonk, NY) to calculate prevalence and associated factors of unsuccessful treatment outcomes. Data are displayed in frequencies and percentages for baseline characteristics and treatment outcomes. The chi-squared test is used for comparing categorical variables by hospital levels. To evaluate associated factors of unsuccessful treatment outcomes, comparison of variables between successful and unsuccessful treatment outcomes by univariate analysis was conducted. For multivariate analysis, multiple logistic regression with "enter" procedure was used. The potential factors for inclusion into multivariate analysis included factors that were significant in univariate analysis, factors with a $P$ value $<0.200$, and factors that were significant in previous studies. Factors that were likely to be potential confounders to others were checked before by cross-tabulation function. The confounding factors would not be included in multivariate analysis. Unrecorded, unperformed, and uncollected data were marked with "unknown statuses." A $P$-value $<$ or equal to 0.05 was an indicator of statistically significant factors.

Ethical consideration. Our study was approved by the Institutional Review Board of the Royal Thai Army Medical Department. The study number was R054h/62_Exp. 


\section{RESULTS}

Of 836 patients with TB receiving treatment in four hospitals, 50 patients were excluded from the study which included 21 patients with extrapulmonary TB, 14 patients who died from causes other than TB or TB-related illnesses, seven patients who were younger than 15 years, four patients with latent TB, and three patients who were transferred out because of health insurance issues. Thus, 786 patients were enrolled in the study. The screening process is depicted in Figure 1.

Baseline characteristics. Among 786 patients included in this study, $70.5 \%$ were male, $52.8 \%$ were laborers, $57.3 \%$ lived in Lopburi, $42.8 \%$ received treatment at Hospital A, $57.3 \%$ received treatment in $\mathrm{F} 2$ hospitals, $65.9 \%$ had at least one comorbid illness, $84.5 \%$ had typical clinical manifestations at the first diagnosis, and only $62.1 \%$ received DOTS. Most patients were 60 years old and older (35.2\%). The median age was 52 (range: 15-91) years. A history of alcohol consumption and cigarette smoking was found among $42.1 \%$ and $46.8 \%$ of the patients, respectively. The most frequent comorbid illnesses were hypertension (28.8\%) and diabetes mellitus (14.4\%). Prevalence of HIV coinfection was 5.5\%. A history of close contact with patients with TB was found among $24.7 \%$ of the patients. Most patients had smearpositive TB $(61.2 \%)$. The rate of sputum specimens of the patients to be smear negative by the second month was $73.7 \%$ after initiating treatment. Most patients had one or no lung lesions at diagnosis (81.9\%). The most frequent lung lesion was reticulonodular infiltration (81.0\%). Most patients showed improvement in chest radiography during the first follow-up (54.3\%) The baseline characteristics are displayed in Table 1.

Prevalence of unsuccessful TB treatment. The outcomes of treatment revealed that $81.3 \%$ of patients had successful pulmonary TB treatment and $18.7 \%$ of patients had unsuccessful pulmonary TB treatment. The unsuccessful outcomes could be classified into four groups: dead (7.3\%), default $(4.7 \%)$, failed $(3.9 \%)$, and transferred out to tertiary center because of DR-TB (2.8\%). The prevalence of unsuccessful TB treatment is shown in Table 2.

Comparing baseline characteristics and treatment outcomes by the hospital level. Baseline characteristics significantly differed between existence of comorbid illnesses $(P<0.001)$, DOTS $(P<0.001)$, sputum AFB smear type $(P<$ $0.001)$, sputum AFB at the second month $(P=0.021)$, and first follow-up of chest radiography $(P<0.001)$. Treatment outcomes significantly differed between $\mathrm{F} 1$ and F2 hospitals $(P<$ 0.001). The comparison result is displayed in Table 3.

Associated factors of unsuccessful pulmonary TB treatment. Adjusted associated factors of unsuccessful pulmonary TB treatment included previously treated TB (AOR: 2.1, 95\% Cl: 1.2-3.7, $P=0.009$ ) existence of comorbid illnesses (AOR: $2.8,95 \% \mathrm{Cl}$ : 1.5-5.0, $P=0.001$ ), DOTS not performed (AOR: 2.5 , 95\% Cl: $1.4-4.5, P=0.002$ ), having multiple lung lesions at first diagnosis (AOR: $3.0,95 \% \mathrm{Cl}$ : $1.7-5.2, P=<0.001)$, and the first follow-up of chest radiography showing no improvement (AOR: $17.7,95 \% \mathrm{Cl}: 8.2-38.0$, $P<0.001$ ), and unknown status of chest radiography in the first follow-up (AOR: 48.1, 95\% Cl: 22.3-103.5, $P<0.001$ ). Adjusted confounding factors included genders, age-groups, hospital levels, previously treated TB, underlying respiratory diseases, existence of comorbid illnesses, DOTS status, lung lesions at diagnosis, and the first follow-up of chest radiography. The results are summarized in Table 4.

\section{DISCUSSION}

This study identified prevalence and associated factors of unsuccessful pulmonary TB treatment in community hospitals located in central Thailand. This study demonstrated a similar prevalence of unsuccessful pulmonary TB treatment in community hospitals as compared with the 2018 WHO report of TB in Thailand ${ }^{2}$ and also studies conducted in Russia, ${ }^{21}$ southern Ethiopia, ${ }^{23}$ and India. ${ }^{24}$ The prevalence was higher

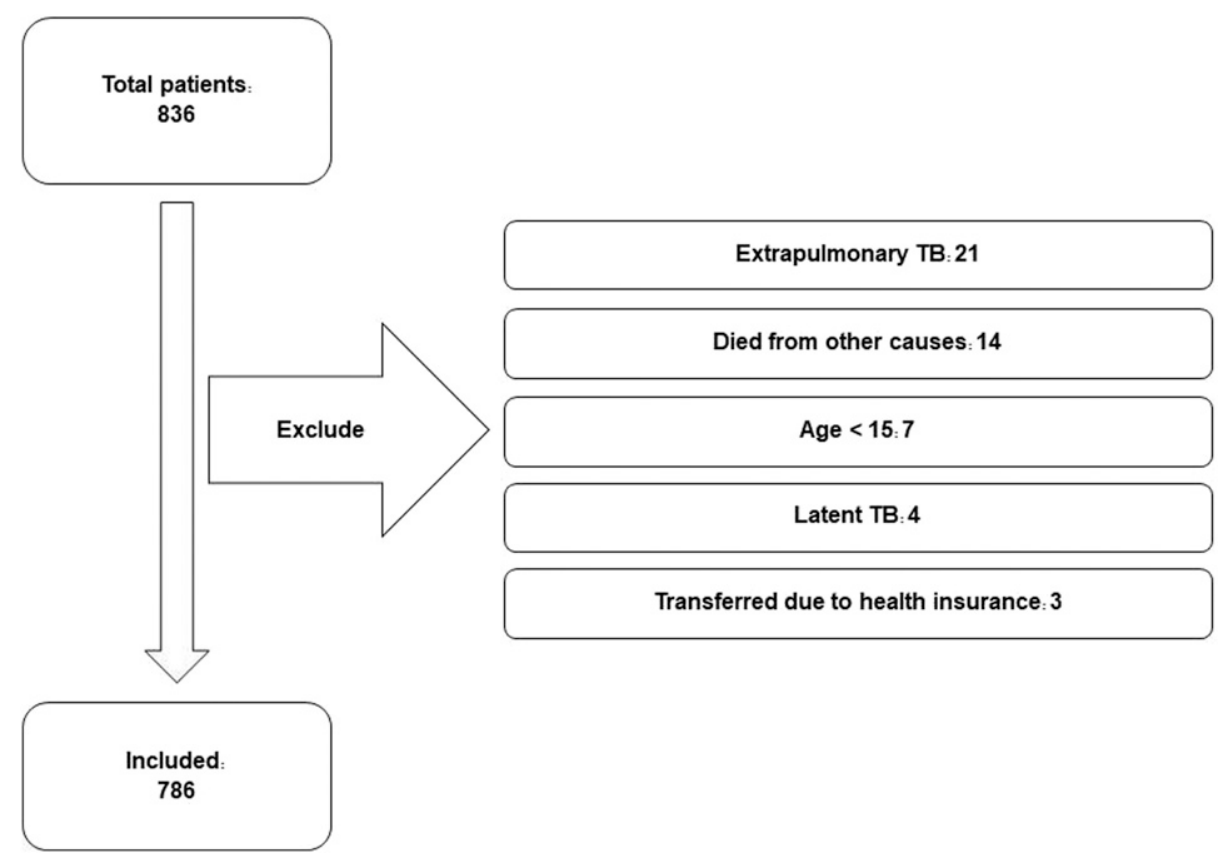

FIGURE 1. Screening process of samples for the study. 
TABLE 1

Baseline characteristics of pulmonary tuberculosis patients $(n=786)$

\begin{tabular}{l}
\hline \\
\hline Gender \\
Male \\
Female \\
Age (years) \\
$15-29$ \\
$30-44$ \\
$45-59$ \\
60 and older \\
Occupation \\
Labor \\
Unemployed \\
Others \\
Province \\
Lopburi \\
Chachoengsad \\
Hospital \\
Hospital A \\
Hospital B \\
Hospital C \\
Hospital D \\
Hospital level \\
F1 hospital \\
F2 hospital \\
Alcohol use \\
Yes \\
No \\
Tobacco use \\
Yes \\
No \\
Comorbid illness \\
Oohdern
\end{tabular}
Characteristic $n(\%)$ $554(70.48)$ $232(29.52)$

74 (9.41)

$177(22.52)$

258 (32.82)

277 (35.24)

415 (52.80)

$272(34.61)$

99 (22.59)

$450(57.25)$

$336(42.75)$

336 (42.75)

$227(28.88)$

$162(20.61)$

$61(7.76)$

$336(42.75)$

$450(57.25)$

362 (42.06)

424 (53.94)

368 (46.82)

418 (53.18)

Underlying hypertension

History of TB contact

Underlying diabetes mellitus

Previously treated TB

HIV coinfection

Underlying respiratory diseases

Underlying chronic kidney disease

Others

Existence of comorbid illnesses

Yes

No

Clinical manifestation at first diagnosis

Typical

Atypical

DOTS status

Performed

Not performed

Unknown†

Sputum AFB at diagnosis

Positive

Negative

Unknown‡

Sputum AFB at second month

Positive

Negative

Unknownł

Chest radiography lesion at diagnosis

One or no lung lesion

Multiple lung lesions

Lung lesion $(n=926) \|$

Reticulonodular infiltration

Lung cavitation

Pleural effusion

Miliary shadow

Others

First follow-up of chest radiography

Improved

Not improved

Unknown\|

* Some patients had more than one comorbid illness.

† One sixty two cases had unknown DOTS status.

$\ddagger$ Some cases did not perform sputum AFB at diagnosis or at 2 months.

$\S$ Some patients had multiple lung lesions.

|| One eighty five cases did not perform follow-up chest radiography.
$226(28.75)$

$194(24.68)$

$113(14.38)$

$111(14.12)$

$43(5.47)$

$41(5.22)$

$9(1.15)$

$101(12.85)$

$518(65.90)$

$268(34.10)$

664 (84.48)

$122(15.52)$

488 (62.09)

136 (17.30)

162 (20.61)

481 (61.20)

286 (36.39)

$19(2.42)$

46 (5.85)

579 (73.66)

161 (20.48)

644 (81.93)

142 (18.07)

637 (81.04)

115 (14.63)

50 (6.36)

8 (1.02)

116 (14.76)

427 (54.33)

174 (22.14)

185 (23.54)
TABLE 2

Classification of pulmonary tuberculosis (TB) patients by treatment outcomes $(n=786)$

\begin{tabular}{lc}
\hline \multicolumn{1}{c}{ Treatment outcome } & $n(\%)$ \\
\hline Successful & \\
Cured & $375(47.71)$ \\
Completed & $264(33.59)$ \\
Unsuccessful & \\
Dead & $57(7.25)$ \\
Default & $37(4.71)$ \\
Failed & $31(3.94)$ \\
Transferred because of multidrug-resistant TB & $22(2.80)$ \\
\hline
\end{tabular}

than studies conducted in Europe, ${ }^{25}$ United Kingdom, ${ }^{26}$ and PR China. ${ }^{16}$

The chi-squared test and independent $t$-test revealed significant differences in baseline characteristics and treatment outcomes between F1 and F2 hospitals. In F2 hospitals, patients were more likely to have comorbid illnesses, never managed or unknown status of DOTS, smear-negative pulmonary TB, have positive sputum AFB smear by the second month, had no improved chest radiography followup, and a higher unsuccessful treatment rate. The differences in quality of facilities, infrastructures, staff, and systems were contributors to these characteristics. In a study in Nigeria, hospitals' quality in TB case management was affected by the DOTS strategy, patients' health knowledge, and efficacy of laboratory investigations used to diagnose and monitor patients. ${ }^{27}$ Although DOTS provides many advantages in all pulmonary TB treatments consisting of smear-negative or -positive, new or retreated cases compared with self-administration therapy, ${ }^{28-30}$ the result of DOTS coverage in this study was still low compared with the $\mathrm{WHO}^{31}$ recommendation and other studies conducted in other regions of Thailand ${ }^{32-34}$ and was not effectively operated by F2 hospitals. Related studies indicated that DOTS coverage was inconsistent across Thailand and compliance to the strategy was poor. $^{32,35}$ There was also unknown status of DOTS in F2 hospitals, which was contributed by poor records of DOTS and unrecorded DOTS data. This poor quality of DOTS data could result in difficult follow-ups of patients' treatment. Studies in India and South Africa have shown that poor diagnostic and treatment outcomes are contributed by healthcare providers' weak knowledge, weak health systems, and weak general management of TB cases by nonphysician healthcare providers. ${ }^{36}$ Moreover, in F2 hospital settings, TB cases are managed by GPs. A study in Indonesia indicated that management of TB cases by GPs may not be in line with the standard guidelines. ${ }^{37}$

Similar to recent studies, previously treated TB was associated with unsuccessful treatment. ${ }^{19,20,38,39}$ A study in Morocco indicated that patients who failed previous treatment were also more likely to fail retreatment. ${ }^{40}$ Also, default in retreatment was more frequent among patients who defaulted from previous treatment. ${ }^{40}$ Moreover, previous treatment outcomes could be used to predict the development of DR-TB. ${ }^{41-43}$

This study had shown that patients who did not receive DOTS were more likely to have unsuccessful treatment outcomes. In a setting of this study, patients usually received DOTS at the clinic, thus resulting in low rates of DOTS applied. It appeared that lack of staff was a major reason that DOTS was inadequately applied in this study. In a study 
TABLE 3

Comparison of baseline characteristics of pulmonary tuberculosis patients and treatment outcomes by hospital levels $(n=786)$

\begin{tabular}{|c|c|c|c|}
\hline \multirow[b]{2}{*}{ Characteristic } & \multicolumn{2}{|c|}{ Hospital level } & \multirow[b]{2}{*}{$P$-value } \\
\hline & F1 hospital, $n(\%)$ & F2 hospital, $n(\%)$ & \\
\hline Gender & & & 0.163 \\
\hline Male & $228(67.86)$ & $326(72.44)$ & \\
\hline Female & $108(32.14)$ & $124(27.56)$ & \\
\hline Age (years) (mean \pm SD) & $53.18 \pm 16.50$ & $51.84 \pm 16.08$ & \\
\hline Existence of comorbid illnesses & & & $<0.001^{\star \star}$ \\
\hline Yes & $183(54.46)$ & 335 (74.44) & \\
\hline No & $153(45.54)$ & $115(25.56)$ & \\
\hline $\begin{array}{l}\text { Directly observed treatment-short } \\
\text { course status }\end{array}$ & & & $<0.001^{\star \star}$ \\
\hline Performed & $318(94.64)$ & $170(37.78)$ & \\
\hline Not performed & $18(5.36)$ & $118(26.22)$ & \\
\hline Unknown* & $0(0.00)$ & $162(36.00)$ & \\
\hline Sputum AFB at diagnosis & & & $<0.001^{\star \star}$ \\
\hline Positive & 235 (69.94) & $246(54.67)$ & \\
\hline Negative & $96(28.57)$ & $190(42.22)$ & \\
\hline Unknown† & 5 (1.49) & $14(3.11)$ & \\
\hline Sputum AFB at the second month & & & $0.021^{\star \star}$ \\
\hline Positive & $14(4.17)$ & $32(7.11)$ & \\
\hline Negative & $264(78.57)$ & $315(70.00)$ & \\
\hline Unknown† & $58(17.26)$ & $103(22.89)$ & \\
\hline Chest radiography lesion at diagnosis & & & 0.537 \\
\hline One or no lung lesion & $272(80.95)$ & $372(82.67)$ & \\
\hline Multiple lung lesions & $64(19.05)$ & $78(17.33)$ & \\
\hline First follow-up of chest radiography & & & $<0.001^{\star \star}$ \\
\hline Improved & $204(60.71)$ & $223(49.56)$ & \\
\hline Not improved & $33(9.82)$ & $141(31.33)$ & \\
\hline Unknownł & $99(29.46)$ & $86(19.11)$ & \\
\hline Treatment outcomes & & & $<0.001^{\star \star}$ \\
\hline Successful & $295(87.80)$ & 344 (76.44) & \\
\hline Unsuccessful & $41(12.20)$ & $106(23.56)$ & \\
\hline
\end{tabular}

conducted in India, patients treated without DOTS had higher risks of adverse outcomes than patients treated with DOTS. ${ }^{44}$ The rural area was indicated to be one of the factors contributing to low adherence to DOTS in studies conducted in Egypt, ${ }^{45}$ China, ${ }^{46}$ and Nepal. ${ }^{47}$ There were various reasons that made the rural area being the contributing factor to low DOTS adherence such as travel costs, illiteracy, poor knowledge of TB, and frequent visits to the clinic. ${ }^{48-51}$ In one study, patients receiving community-based DOTS achieved successful treatment and curative treatment more than selfadministered therapy. ${ }^{29}$ In another study, completion was $100 \%$ in patients receiving community-based DOTS. ${ }^{52}$ This strategy could enlighten a new model for treatment of TB in rural communities.

In this study, the existence of comorbid illnesses was associated with unsuccessful treatment of pulmonary TB. In resource-limited countries, comorbidity of TB with both communicable and noncommunicable diseases is common; thus, a high efficacy of responses to both TB and other comorbid illnesses is required. ${ }^{53}$ However, this attempt is difficult to achieve in resource-limited countries. Moreover, noncommunicable diseases increase individuals' vulnerability to TB. ${ }^{53}$ Comorbid illnesses and poor health status also increase mortality rates among patients with TB. ${ }^{54}$ In addition, from this study, $35.2 \%$ were patients aged 60 years and older. Treatment of TB in older patients is more complicated than in other age-groups because of impaired immunity from underlying conditions, increased incidence of drug side effects, and limitations due to polypharmacy. ${ }^{55}$
Multiple lung lesions are associated with unsuccessful pulmonary TB treatment. In this study, $21.7 \%$ of patients with cavity and $62.50 \%$ of patients with miliary shadow experienced unsuccessful treatment. Studies conducted in the United Kingdom and Brazil indicated that lung cavitation was prone to high mycobacterial load. ${ }^{56,57}$ Mycobacterium tuberculosis is more likely to lodge in these cavities that are less affected by anti-TB drug actions, resulting in poor treatment success. ${ }^{58}$ In a study in PR China, patients with miliary shadow were more likely to have unsuccessful treatment outcomes, ${ }^{16}$ whereas a study conducted in the Netherlands stated that miliary TB was one of the predictors for mortality in both drug susceptible- and drug resistant-tuberculosis. ${ }^{59,60}$ This study indicated that patients with more lung lesions such as coexistence between reticulonodular infiltration and cavitation or miliary shadow were more likely to have unsuccessful treatment outcomes because of higher mycobacterial load and low efficacy of anti-TB drugs to penetrate these lung lesions. Interpretation of chest radiography by specialists such as radiologists in tertiary care centers could be more accurate than by GPs; thus, diagnosis and follow-ups would be successful in tertiary care centers.

Patients showing no improvement in chest radiography during the first follow-up also revealed a higher likelihood to have unsuccessful outcomes. According to the clinical practice guidelines in Thailand, following up chest radiography first at the second month after initiation of treatment and second at the end of treatment is recommended. ${ }^{61}$ Chest radiography is useful to diagnose and follow up in smear-negative TB cases $^{62,63}$ as a large proportion of smear-negative TB cases 
TABLE 4

Univariate and multivariate analysis of associated factors of unsuccessful pulmonary tuberculosis (TB) treatment outcomes in rural Thailand, 2013-2018 $(n=786)$

\begin{tabular}{|c|c|c|c|c|c|c|c|c|}
\hline \multirow[b]{2}{*}{ Characteristic } & \multicolumn{2}{|c|}{ Outcomes } & \multirow[b]{2}{*}{ Crude OR } & \multirow[b]{2}{*}{$95 \% \mathrm{Cl}$} & \multirow[b]{2}{*}{$P$-value } & \multirow[b]{2}{*}{ Adjusted OR } & \multirow[b]{2}{*}{$95 \% \mathrm{Cl}$} & \multirow[b]{2}{*}{$P$-value } \\
\hline & Successful, $n(\%)$ & Unsuccessful, $n(\%)$ & & & & & & \\
\hline \multicolumn{9}{|l|}{ Gender } \\
\hline Female & 197 (84.91) & 35 (15.09) & 1.00 & & & 1.00 & & \\
\hline Male & $442(79.78)$ & $112(20.22)$ & 1.43 & $0.94-2.16$ & 0.094 & 1.04 & $0.62-1.75$ & 0.890 \\
\hline \multicolumn{9}{|l|}{ Age (years) } \\
\hline $15-29$ & 66 (89.19) & 8 (10.81) & 1.00 & & & 1.00 & & \\
\hline $30-44$ & 145 (81.92) & $32(18.60)$ & 1.82 & $0.80-4.20$ & 0.156 & 1.92 & $0.73-5.03$ & 0.185 \\
\hline $45-59$ & $210(81.40)$ & $48(18.60)$ & 1.89 & $0.85-4.19$ & 0.119 & 1.96 & $0.77-5.00$ & 0.161 \\
\hline 60 and older & $218(78.70)$ & $59(21.30)$ & 2.23 & $1.02-4.91$ & 0.046 & 1.63 & $0.64-4.16$ & 0.309 \\
\hline \multicolumn{9}{|l|}{ Occupation } \\
\hline Labor & 338 (81.45) & 77 (18.55) & 1.00 & & & & & \\
\hline Unemployed & $210(77.21)$ & $62(22.79)$ & 1.30 & $0.89-1.89$ & 0.177 & & & \\
\hline Others & 91 (91.92) & 8 (8.08) & 0.39 & $0.18-0.83$ & 0.015 & & & \\
\hline Province & & & & & & & & \\
\hline Chachoengsao & $295(87.80)$ & 41 (12.20) & 1.00 & & & & & \\
\hline Lopburi & $344(76.44)$ & $106(23.56)$ & 2.22 & $1.50-3.28$ & $<0.001$ & & & \\
\hline Hospital & & & & & & & & \\
\hline Hospital A & $295(87.80)$ & $41(12.20)$ & 1.00 & & & & & \\
\hline Hospital B & $133(82.10)$ & $29(17.90)$ & 0.64 & $0.38-1.07$ & 0.088 & & & \\
\hline Hospital C & $164(72.25)$ & $63(27.75)$ & 1.76 & $1.07-2.89$ & 0.025 & & & \\
\hline Hospital D & 47 (77.05) & $14(22.95)$ & 1.37 & $0.67-2.81$ & 0.395 & & & \\
\hline Hospital level & & & & & & & & \\
\hline F1 hospital & 295 (87.80) & $41(12.20)$ & 1.00 & & & 1.00 & & \\
\hline F2 hospital & $344(76.44)$ & $106(23.56)$ & 2.22 & $1.50-3.29$ & $<0.001$ & 1.73 & $0.95-3.17$ & 0.075 \\
\hline Alcohol use & & & & & & & & \\
\hline No & 341 (80.42) & 83 (19.58) & 1.00 & & & & & \\
\hline Yes & $298(82.32)$ & $64(17.68)$ & 0.88 & $0.62-1.27$ & 0.497 & & & \\
\hline Tobacco use & & & & & & & & \\
\hline No & 341 (81.58) & 77 (18.42) & 1.00 & & & & & \\
\hline Yes & 298 (80.98) & 70 (19.02) & 1.04 & $0.73-1.49$ & 0.829 & & & \\
\hline History of TB cont & & & & & & & & \\
\hline No & $481(81.25)$ & $111(18.75)$ & 1.00 & & & & & \\
\hline Yes & $158(81.44)$ & 36 (18.56) & 0.99 & $0.65-1.50$ & 0.952 & & & \\
\hline Previously treated & & & & & & & & \\
\hline No & $566(83.85)$ & 109 (16.15) & 1.00 & & & & & \\
\hline Yes & $73(65.77)$ & 38 (34.23) & 2.70 & $1.74-4.21$ & $<0.001$ & 2.11 & $1.20-3.71$ & $0.009^{\star}$ \\
\hline Underlying diabete & & & & & & & & \\
\hline No & $546(81.13)$ & 127 (18.87) & 1.00 & & & & & \\
\hline Yes & 93 (82.30) & 20 (17.70) & 0.93 & $0.55-1.56$ & 0.768 & & & \\
\hline HIV coinfection & & & & & & & & \\
\hline No & $606(81.56)$ & $137(18.44)$ & 1.00 & & & & & \\
\hline Yes & $33(76.74)$ & $10(23.26)$ & 1.34 & $0.65-2.79$ & 0.432 & & & \\
\hline Underlying respira & ases & & & & & & & \\
\hline No & $612(82.15)$ & $133(17.85)$ & 1.00 & & & & & \\
\hline Yes & $27(65.85)$ & $14(34.15)$ & 2.39 & $1.22-4.68$ & 0.011 & 1.15 & $0.49-2.70$ & 0.741 \\
\hline Underlying chronic & disease & & & & & & & \\
\hline No & $632(81.34)$ & 145 (18.66) & 1.00 & & & & & \\
\hline Yes & 7 (77.78) & 2 (22.22) & 1.25 & $0.26-6.06$ & 0.786 & & & \\
\hline Existence of como & sses & & & & & & & \\
\hline No & $243(90.67)$ & 25 (9.33) & 1.00 & & & 1.00 & & \\
\hline Yes & $396(76.45)$ & $122(23.55)$ & 3.00 & $1.89-4.74$ & $<0.001$ & 2.76 & $1.53-4.99$ & $0.001^{*}$ \\
\hline Clinical manifestat & st diagnosis & & & & & & & \\
\hline Typical & $541(81.48)$ & 123 (18.52) & 1.00 & & & & & \\
\hline Atypical & $98(80.33)$ & 24 (19.67) & 1.08 & $0.66-1.75$ & 0.765 & & & \\
\hline Directly observed & it-short cours & status & & & & & & \\
\hline Performed & 418 (85.66) & $70(14.34)$ & 1.00 & & & & & \\
\hline Not performed & $88(64.71)$ & 48 (35.29) & 3.26 & $2.11-5.02$ & $<0.001$ & 2.52 & $1.40-4.54$ & 0.002 \\
\hline Unknown† & 133 (82.10) & $29(17.90)$ & 1.30 & $0.81-2.09$ & 0.276 & 1.28 & $0.65-2.53$ & 0.475 \\
\hline Sputum AFB at dia & & & & & & & & \\
\hline Negative & $230(72.33)$ & $88(27.67)$ & 1.00 & & & & & \\
\hline Positive & $393(87.53)$ & $56(12.47)$ & 0.92 & $0.63-1.34$ & 0.659 & & & \\
\hline Unknownł & $16(84.21)$ & 3 (15.79) & 0.77 & $0.22-2.74$ & 0.686 & & & \\
\hline Sputum AFB at the & month & & & & & & & \\
\hline Negative & 528 (91.19) & $51(8.81)$ & 1.00 & & & & & \\
\hline Positive & $32(69.57)$ & $14(30.43)$ & 4.53 & 2.27-9.04 & $<0.001$ & & & \\
\hline Unknown‡ & 79 (49.07) & $82(50.93)$ & 10.75 & $7.05-16.39$ & $<0.001$ & & & \\
\hline
\end{tabular}


TABLE 4

Continued

\begin{tabular}{|c|c|c|c|c|c|c|c|c|}
\hline \multirow[b]{2}{*}{ Characteristic } & \multicolumn{2}{|c|}{ Outcomes } & \multirow[b]{2}{*}{ Crude OR } & \multirow[b]{2}{*}{$95 \% \mathrm{Cl}$} & \multirow[b]{2}{*}{$P$-value } & \multirow[b]{2}{*}{ Adjusted OR } & \multirow[b]{2}{*}{$95 \% \mathrm{Cl}$} & \multirow[b]{2}{*}{$P$-value } \\
\hline & Successful, $n(\%)$ & Unsuccessful, $n(\%)$ & & & & & & \\
\hline \multicolumn{9}{|c|}{ Chest radiography lesion at diagnosis } \\
\hline One or no lung lesion & $539(83.70)$ & $105(16.30)$ & 1.00 & & & 1.00 & & \\
\hline Multiple lung lesions & $100(70.42)$ & $42(29.58)$ & 2.16 & $1.42-3.27$ & $<0.001$ & 2.98 & $1.72-5.17$ & $<0.001^{\star}$ \\
\hline \multicolumn{9}{|l|}{ Reticulonodular infiltration } \\
\hline No & $126(84.56)$ & $23(15.44)$ & 1.00 & & & & & \\
\hline Yes & $513(80.53)$ & $124(19.47)$ & 1.32 & $0.81-2.16$ & 0.257 & & & \\
\hline \multicolumn{9}{|l|}{ Cavitation } \\
\hline No & $549(81.82)$ & $122(18.18)$ & 1.00 & & & & & \\
\hline Yes & $90(78.26)$ & $25(21.74)$ & 1.25 & $0.77-2.03$ & 0.367 & & & \\
\hline \multicolumn{9}{|l|}{ Pleural effusion } \\
\hline No & $602(81.79)$ & $134(18.21)$ & 1.00 & & & & & \\
\hline Yes & $37(74.00)$ & $13(26.00)$ & 1.58 & $0.82-3.05$ & 0.175 & & & \\
\hline \multicolumn{9}{|l|}{ Miliary shadow } \\
\hline No & $636(81.75)$ & $142(18.25)$ & 1.00 & & & & & \\
\hline Yes & $3(37.50)$ & $5(62.50)$ & 7.47 & $1.76-31.60$ & 0.006 & & & \\
\hline \multicolumn{9}{|c|}{ First follow-up of chest radiography } \\
\hline Improved & $418(97.89)$ & $9(2.11)$ & 1.00 & & & 1.00 & & \\
\hline Not improved & $116(66.67)$ & 58 (33.33) & 23.22 & $11.17-48.27$ & $<0.001$ & 17.68 & $8.23-37.99$ & $<0.001^{\star}$ \\
\hline Unknown§ & $105(56.76)$ & $80(43.24)$ & 35.39 & $17.20-72.81$ & $<0.001$ & 48.08 & $22.33-103.51$ & $<0.001^{\star}$ \\
\hline
\end{tabular}

develop in consistent with chest radiography for TB. ${ }^{63}$ A study in Indonesia indicated that chest radiography grading scores correlated with TB severity and response to treatment. ${ }^{64}$ One related study suggested that chest radiography without improvement may indicate DR-TB or other lung lesions. ${ }^{65}$

This study had some limitations. First, data on anti-TB regimens were not collected because of varying and modified regimens and unequal extended periods of treatment among patients; however, anti-TB regimens could constitute an important factor for treatment outcomes. As one study had discovered that patients with resistance to the second-line drug regimen could result in poor treatment outcomes. ${ }^{66}$ Second, MDR-TB accounts for $2.2 \%$ of new cases and $24 \%$ of related cases treated in Thailand. ${ }^{2}$ Success rates of MDR-TB treatment totaled only $60 \%$ in 2015 in Thailand. ${ }^{2}$ Thus, MDR-TB could serve as a factor for unsuccessful treatments. ${ }^{1}$ In a study conducted in Pakistan and the Netherlands, MDR-TB and extensively DR-TB were predictive factors of unsuccessful treatment outcomes. ${ }^{60,66}$ However, because of limited resources in community hospitals, MDR-TB cases cannot be diagnosed in this setting. Thus, no records of MDR-TB were available in community hospitals. Third, there were some variables with missing data in this study, which included the DOTS status (20.61\%), sputum AFB at diagnosis (2.42\%), sputum AFB at the second month (20.48\%), and first follow-up of chest radiography (23.54\%). Two variables (DOTS status and first follow-up of chest radiography) were included into multivariate analysis. We prevent the selection bias by labeling these missing data as the "unknown status" category in each variable. Thus, all cases were included into multivariate analysis.

One recommendation is for $\mathrm{F} 2$ hospitals to apply approach strategies in communities for earlier diagnosis and better follow-up for patients. Consultation and communication between GPs and specialists should be conducted to optimize ultimate treatment outcomes by GPs. Special training in radiography interpretation for healthcare providers should be emphasized to expand TB care in communities.
This study provided data on prevalence and associated factors of unsuccessful pulmonary TB treatment in community hospitals of Thailand. These data could assist with distributing and planning of healthcare resources to improve public well-being. For healthcare practitioners, it serves to highlight the importance of diagnosis, treatment, and monitoring of patients with TB.

Received July 30, 2019. Accepted for publication December 2, 2019. Published online January 13, 2020.

Acknowledgments: We would like to express our special thanks to the staff of Tha Luang, Tha Wung, Pattnanikom, and Sanamchaikate hospitals for providing data and resources in our study.

Financial support: Our study was funded by the Phramongkutklao College of Medicine.

Authors' addresses: Sakarn Charoensakulchai, Manasak Limsakul, Inkharat Saengungsumalee, Sirawich Usawachoke, Aticha Udomdech, and Anintita Pongsaboripat, Phramongkutklao College of Medicine, Bangkok, Thailand, E-mails: karn.skch@gmail.com, mozz4061@gmail.com, dog-holiday@hotmail.co.th, sirawich.u@outlook.com, atichau.1996@ gmail.com, and aninp17@hotmail.com. Wisit Kaewput, Boonsub Sakboonyarat, and Ram Rangsin, Department of Military and Community Medicine, Phramongkutklao College of Medicine, Bangkok, Thailand, E-mails: wisitnephro@gmail.com, countryside.physician@ gmail.com, and r_rangsin@yahoo.com. Picha Suwannahitatorn and Phunlerd Piyaraj, Department of Parasitology, Phramongkutklao College of Medicine, Bangkok, Thailand, E-mails: atnox25@live.com and p_phunlerd@yahoo.com. Mathirut Mungthin, Department of Pharmacology, Phramongkutklao College of Medicine, Bangkok, Thailand, E-mail: mathirut@hotmail.com.

\section{REFERENCES}

1. Glaziou P, Floyd K, Raviglione MC, 2018. Global Epidemiology of Tuberculosis. Seminars in Respiratory and Critical Care Medicine. New York, NY: Thieme Medical Publishers, 271-285.

2. WHO, 2018. Global Tuberculosis Report 2018. Geneva, Switzerland: World Health Organization.

3. Nair N, Wares F, Sahu S, 2010. Tuberculosis in the WHO south east Asia region. Bull World Health Organ 88: 164.

4. Corbett EL, Watt CJ, Walker N, Maher D, Williams BG, Raviglione MC, Dye C, 2003. The growing burden of tuberculosis: global 
trends and interactions with the HIV epidemic. Arch Intern Med 163: 1009-1021.

5. Sharma S, Mohan A, Kadhiravan T, 2005. HIV-TB co-infection: epidemiology, diagnosis \& management. Indian J Med Res 121: 550-567.

6. Aaron L, Saadoun D, Calatroni I, Launay O, Memain N, Vincent V, Marchal G, Dupont B, Bouchaud O, Valeyre D, 2004. Tuberculosis in HIV-infected patients: a comprehensive review. Clin Microbiol Infect 10: 388-398.

7. Havlir DV, Getahun H, Sanne I, Nunn P, 2008. Opportunities and challenges for HIV care in overlapping HIV and TB epidemics. JAMA 300: 423-430.

8. Bureau of Tuberculosis, Ministry of Public Health, 2018. National Tuberculosis Control Programme Guideline, Thailand, 2018. Bangkok, Thailand: Ministry of Public Health.

9. International Health Policy Program, Ministry of Public Health, 2017. Disability-Adjusted Life Years: DALYs. Nonthaburi, Thailand: Ministry of Public Health.

10. Department of Economic, United Nations, 2018. Population of Urban and Rural Areas at Mid-Year (Thousands) and Percentage Urban, 2018. Available at: https://population.un.org/wup/ Download/. Accessed September 28, 2019.

11. Tangcharoensathien $V$, Witthayapipopsakul $W$, Panichkriangkrai W, Patcharanarumol W, Mills A, 2018. Health systems development in Thailand: a solid platform for successful implementation of universal health coverage. Lancet 391: 1205-1223.

12. Pengpid S, Peltzer K, Puckpinyo A, Tiraphat S, Viripiromgool S, Apidechkul T, Sathirapanya C, Leethongdee S, Chompikul J, Mongkolchati A, 2016. Knowledge, attitudes, and practices about tuberculosis and choice of communication channels in Thailand. J Infect Dev Ctries 10: 694-703.

13. Cai J, Wang X, Ma A, Wang Q, Han X, Li Y, 2015. Factors associated with patient and provider delays for tuberculosis diagnosis and treatment in Asia: a systematic review and metaanalysis. PLoS One 10: e0120088.

14. The Healthcare Accreditation Institute (Public Organization), 2017. Hospital Accreditation Status, 2017. Available at: http:// www.ha.or.th/EN/Article/The\%20hospital\%20is\%20accredited. Accessed September 28, 2019.

15. Thai Health Coding Center, 2011. Classification Criteria for Healthcare Center under Ministry of Public Health Levels According to Geographic Information System (GIS). Available at: http://www.thcc.or.th/download/GIS54.pdf. Accessd September 28, 2019.

16. Wen Y, Zhang Z, Li X, Xia D, Ma J, Dong Y, Zhang X, 2018. Treatment outcomes and factors affecting unsuccessful outcome among new pulmonary smear positive and negative tuberculosis patients in Anqing, China: a retrospective study. BMC Infect Dis 18: 104

17. Muture BN, Keraka MN, Kimuu PK, Kabiru EW, Ombeka VO, Oguya F, 2011. Factors associated with default from treatment among tuberculosis patients in Nairobi province, Kenya: a case control study. BMC Public Health 11: 696.

18. Melese A, Zeleke B, 2018. Factors associated with poor treatment outcome of tuberculosis in Debre Tabor, northwest Ethiopia. BMC Res Notes 11: 25.

19. Berhe G, Enquselassie F, Aseffa A, 2012. Treatment outcome of smear-positive pulmonary tuberculosis patients in Tigray Region, Northern Ethiopia. BMC Public Health 12: 537.

20. de Albuquerque MdeF, Ximenes RA, Lucena-Silva N, Souza WV, Dantas AT, Dantas OM, Rodrigues LC, 2007. Factors associated with treatment failure, dropout, and death in a cohort of tuberculosis patients in Recife, Pernambuco State, Brazil. Cad Saúde Pública 23: 1573-1582.

21. Jakubowiak W, Bogorodskaya E, Borisov E, Danilova D, Kourbatova E, 2007. Risk factors associated with default among new pulmonary TB patients and social support in six Russian regions. Int J Tuberc Lung Dis 11: 46-53.

22. WHO, 2014. Treatment of Tuberculosis: Guidelines. Geneva, Switzerland: World Health Organization.

23. Muñoz-Sellart M, Cuevas L, Tumato M, Merid Y, Yassin M, 2010. Factors associated with poor tuberculosis treatment outcome in the southern region of Ethiopia. Int J Tuberc Lung Dis 14: 973-979.
24. Jackson C, Stagg H, Doshi A, Pan D, Sinha A, Batra R, Batra S, Abubakar I, Lipman M, 2017. Tuberculosis treatment outcomes among disadvantaged patients in India. Public Health Action 7: 134-140.

25. Faustini A, Hall A, Perucci C, 2005. Tuberculosis treatment outcomes in Europe: a systematic review. Eur Respir J 26: 503-510.

26. Ditah IC, Reacher M, Palmer C, Watson JM, Innes J, Kruijshaar ME, Luma HN, Abubakar I, 2008. Monitoring tuberculosis treatment outcome: analysis of national surveillance data from a clinical perspective. Thorax 63: 440-446.

27. Tobin-West $\mathrm{Cl}$, Isodje A, 2016. Quality and rural-urban comparison of tuberculosis care in Rivers State, Nigeria. Pan Afr Med J 24.

28. DeRiemer K, García-García L, Bobadilla-del-Valle M, PalaciosMartínez M, Martínez-Gamboa A, Small PM, Sifuentes-Osornio J, Ponce-de-León A, 2005. Does DOTS work in populations with drug-resistant tuberculosis? Lancet 365: 1239-1245.

29. Zhang H, Ehiri J, Yang H, Tang S, Li Y, 2016. Impact of community-based DOT on tuberculosis treatment outcomes: a systematic review and meta-analysis. PLoS One 11: e0147744.

30. Yin J, Yuan J, Hu Y, Wei X, 2016. Association between directly observed therapy and treatment outcomes in multidrugresistant tuberculosis: a systematic review and meta-analysis. PLoS One 11: e0150511.

31. World Health Organization Communicable Diseases Cluster, 1999. What is DOTS?: A Guide to Understanding the WHOrecommended TB Control Strategy Known as DOTS. Geneva, Switzerland: World Health Organization.

32. Pungrassami $P$, Johnsen $S$, Chongsuvivatwong V, Olsen J, Sørensen $\mathrm{H}, 2002$. Practice of directly observed treatment (DOT) for tuberculosis in southern Thailand: comparison between different types of DOT observers. Int J Tuberc Lung Dis 6: 389-395.

33. Dye C, Watt CJ, Bleed DM, Williams BG, 2003. What is the limit to case detection under the DOTS strategy for tuberculosis control? Tuberculosis 83: 35-43.

34. Jittimanee S, Vorasingha J, Mad-asin W, Nateniyom S, Rienthong S, Varma JK, 2009. Tuberculosis in Thailand: epidemiology and program performance, 2001-2005. Int J Infect Dis 13: 436-442.

35. Soonthorndhana A, Vorasiriamon Y, Theobald S, Smith H, 2004. Community Perceptions and Experiences of TB in Kanchanaburi, Thailand: A Gender Equity Analysis. Nakhon Pathom, Thailand: Institute for Population and Social Research, Mahidol University.

36. Padayatchi N, Daftary A, Naidu N, Naidoo K, Pai M, 2019. Tuberculosis: treatment failure, or failure to treat? Lessons from India and South Africa. BMJ Global Health 4: e001097.

37. Mahendradhata Y, Lestari T, Probandari A, Indriarini LE, Burhan E, Mustikawati D, Utarini A, 2015. How do private general practitioners manage tuberculosis cases? A survey in eight cities in Indonesia. BMC Res Notes 8: 564.

38. Anunnatsiri S, Chetchotisakd P, Wanke C, 2005. Factors associated with treatment outcomes in pulmonary tuberculosis in northeastern Thailand. Southeast Asian J Trop Med Public Health 36: 324-330.

39. Babalık A, Kılıçaslan Z, Kızıltaş Ş, Gencer S, Öngen G, 2013. A retrospective case-control study, factors affecting treatment outcomes for pulmonary tuberculosis in Istanbul, Turkey. Balkan Med J 30: 204.

40. Dooley KE, Lahlou O, Knudsen J, Elmessaoudi MD, Cherkaoui I, El Aouad R, 2011. Risk factors for tuberculosis treatment failure, default, or relapse and outcomes of retreatment in Morocco. BMC Public Health 11: 140.

41. Kritski AL, de Jesus LSR, Werneck-Barroso E, Vieira MAMS, Andrade MK, Haffner A, Riley LW, 1997. Retreatment tuberculosis cases: factors associated with drug resistance and adverse outcomes. Chest 111: 1162-1167.

42. Rifat M, Hall J, Oldmeadow C, Husain A, Hinderaker SG, Milton $\mathrm{AH}, 2015$. Factors related to previous tuberculosis treatment of patients with multidrug-resistant tuberculosis in Bangladesh. BMJ Open 5: e008273.

43. Rifat M, Milton AH, Hall J, Oldmeadow C, Islam MA, Husain A, Akhanda MW, Siddiquea BN, 2014. Development of multidrug 
resistant tuberculosis in Bangladesh: a case-control study on risk factors. PLoS One 9: e105214.

44. Balasubramanian V, Oommen K, Samuel R, 2000. DOT or not? Direct observation of anti-tuberculosis treatment and patient outcomes, Kerala State, India. Int J Tuberc Lung Dis 4: 409-413.

45. Nour El Din M, Elhoseeny T, Mohsen A, 2013. Factors affecting defaulting from DOTS therapy under the national programme of tuberculosis control in Alexandria, Egypt. East Mediterr Health J 19: 107-113.

46. Xu W, Lu W, Zhou Y, Zhu L, Shen H, Wang J, 2009. Adherence to anti-tuberculosis treatment among pulmonary tuberculosis patients: a qualitative and quantitative study. BMC Health Serv Res 9: 169.

47. Lamsal D, Lewis O, Smith S, Jha N, 2009. Factors related to defaulters and treatment failure of tuberculosis patients in the DOTS program in the Sunsari district of Eastern Nepal. SAARC $J$ Tuber Lung Dis HIVIAIDS 6: 25-30.

48. Bam TS, Gunneberg C, Chamroonsawasdi K, Bam D, Aalberg O, Kasland O, Shiyalap K, Srisorrachatr S, 2006. Factors affecting patient adherence to DOTS in urban Kathmandu, Nepal. Int $J$ Tuberc Lung Dis 10: 270-276.

49. McLaren ZM, Milliken AA, Meyer AJ, Sharp AR, 2016. Does directly observed therapy improve tuberculosis treatment? More evidence is needed to guide tuberculosis policy. BMC Infect Dis 16: 537.

50. Vijay S, Kumar P, Chauhan LS, Vollepore BH, Kizhakkethil UP, Rao SG, 2010. Risk factors associated with default among new smear positive TB patients treated under DOTS in India. PLOS One 5: e10043.

51. Lorent N, Choun K, Malhotra S, Koeut P, Thai S, Khun KE, Colebunders R, Lynen L, 2015. Challenges from tuberculosis diagnosis to care in community-based active case finding among the urban poor in cambodia: a mixed-methods study. PLoS One 10: e0130179.

52. Dobler CC, Korver S, Batbayar O, Oyuntsetseg S, Tsolmon B, Wright C, Solongo B, Marais BJ, 2015. Success of communitybased directly observed anti-tuberculosis treatment in Mongolia. Int J Tuberc Lung Dis 19: 657-662.

53. Marais BJ, Loennroth K, Lawn SD, Migliori GB, Mwaba P, Glaziou P, Bates M, Colagiuri R, Zijenah L, Swaminathan S, 2013. Tuberculosis comorbidity with communicable and non-communicable diseases: integrating health services and control efforts. Lancet Infect Dis 13: 436-448.
54. Rao VK, Lademarco EP, Fraser VJ, Kollef MH, 1998. The impact of comorbidity on mortality following in-hospital diagnosis of tuberculosis. Chest 114: 1244-1252.

55. Rajagopalan S, Yoshikawa T, 2000. Tuberculosis in the elderly. Z Gerontol Geriatr 33: 374-380.

56. Perrin F, Woodward N, Phillips P, McHugh T, Nunn A, Lipman M, Gillespie S, 2010. Radiological cavitation, sputum mycobacterial load and treatment response in pulmonary tuberculosis. Int $J$ Tuberc Lung Dis 14: 1596-1602.

57. Palaci M, Dietze R, Hadad DJ, Ribeiro FKC, Peres RL, Vinhas SA, Maciel ELN, do Valle Dettoni V, Horter L, Boom WH, 2007. Cavitary disease and quantitative sputum bacillary load in cases of pulmonary tuberculosis. J Clin Microbiol 45: 4064-4066.

58. Horsburgh Jr. CR, Barry III. CE, Lange C, 2015. Treatment of tuberculosis. N Engl J Med 373: 2149-2160.

59. Pradipta I, Van't Boveneind-Vrubleuskaya N, Akkerman O, Alffenaar J, Hak E, 2019. Predictors for treatment outcomes among patients with drug-susceptible tuberculosis in the Netherlands: a retrospective cohort study. Clin Microbiol Infect 25: 761.

60. Pradipta IS, van't Boveneind-Vrubleuskaya N, Akkerman OW, Alffenaar J-WC, Hak E, 2019. Treatment outcomes of drugresistant tuberculosis in the Netherlands, 2005-2015. Antimicrob Resist Infect Control 8: 115.

61. Department of Medical Services, Ministry of Public Health, 2018. Clinical Practice Guideline (CPG) of Tuberculosis Treatment in Adult. Nonthaburi, Thailand: Ministry of Public Health.

62. Ryu YJ, 2015. Diagnosis of pulmonary tuberculosis: recent advances and diagnostic algorithms. Tuberc Respir Dis 78: 64-71.

63. Harries A, Banda H, Boeree M, Welby S, Wirima J, Subramanyam V, Maher D, Nunn P, 1998. Management of pulmonary tuberculosis suspects with negative sputum smears and normal or minimally abnormal chest radiographs in resource-poor settings. Int J Tuberc Lung Dis 2: 999-1004.

64. Ralph AP, Ardian M, Wiguna A, Maguire GP, Becker NG, Drogumuller G, Wilks MJ, Waramori G, Tjitra E, Kenagalem E, 2010. A simple, valid, numerical score for grading chest x-ray severity in adult smear-positive pulmonary tuberculosis. Thorax 65: 863-869.

65. Roy M, Ellis S, 2010. Radiological diagnosis and follow-up of pulmonary tuberculosis. Postgrad Med J 86: 663-674.

66. Javaid A, Ullah I, Masud H, Basit A, Ahmad W, Butt Z, Qasim M, 2018. Predictors of poor treatment outcomes in multidrugresistant tuberculosis patients: a retrospective cohort study. Clin Microbiol Infect 24: 612-617. 